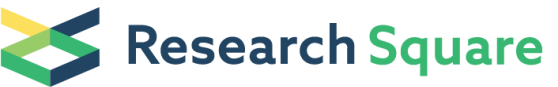

\section{Metabolomic analysis of biosynthesis mechanism of $\varepsilon$-polylysine produced by Streptomyces diastatochromogenes}

\section{Ziyuan Wang}

State Key Laboratory of Food Nutrition and Safety, Laboratory of Industrial Fermentation Microbiology, Ministry of Education, Tianjin University of Science and Technology, No 29, 13th, Avenue, Tianjin Economic and Technological Development Area (TEDA), Tia

\section{Fengzhu Guo}

State Key Laboratory of Food Nutrition and Safety, Laboratory of Industrial Fermentation Microbiology, Ministry of Education, Tianjin University of Science and Technology, No 29, 13th, Avenue, Tianjin Economic and Technological Development Area (TEDA), Tia

\section{Tianyu Dong}

State Key Laboratory of Food Nutrition and Safety, Laboratory of Industrial Fermentation Microbiology, Ministry of Education, Tianjin University of Science and Technology, No 29, 13th, Avenue, Tianjin Economic and Technological Development Area (TEDA), Tia

\section{Zhilei Tan}

State Key Laboratory of Food Nutrition and Safety, Laboratory of Industrial Fermentation Microbiology, Ministry of Education, Tianjin University of Science and Technology, No 29, 13th, Avenue, Tianjin Economic and Technological Development Area (TEDA), Tia

\section{Mohamed Abdelraof}

Genetic engineering \& Biotechnology research Division, National Research Centre, Dokki, 12622, Giza, Egypt

\section{Jiandong Cui ( $\square$ jdcui@tust.edu.cn )}

Tianjin University of Science and Technology

\section{Shiru Jia}

State Key Laboratory of Food Nutrition and Safety, Laboratory of Industrial Fermentation Microbiology, Ministry of Education, Tianjin University of Science and Technology, No 29, 13th, Avenue, Tianjin Economic and Technological Development Area (TEDA), Tia

\section{Research}

Keywords: $\varepsilon$-polylysine, Streptomyces diastatochromogenes, Biosynthesis mechanism, Metabolomics

Posted Date: June 22nd, 2020 
DOl: https://doi.org/10.21203/rs.3.rs-32778/v2

License: (c) (1) This work is licensed under a Creative Commons Attribution 4.0 International License. Read Full License 
The authors have withdrawn this preprint from Research Square 